\title{
Alterations in transmural strains adjacent to ischemic myocardium during acute midcircumflex occlusion
}

Filiberto Rodriguez, $\mathrm{MD}^{\mathrm{a}}$

Frank Langer, $\mathrm{MD}^{\mathrm{a}}$

Katherine B. Harrington, $\mathrm{BA}^{\mathrm{a}}$

Allen Cheng, MD

George T. Daughters, $\mathrm{MS}^{\mathrm{a}, \mathrm{b}}$

John C. Criscione, $\mathrm{MD}, \mathrm{PhD}^{\mathrm{C}}$

Neil B. Ingels, $\mathrm{PhD}^{\mathrm{a}, \mathrm{b}}$

D. Craig Miller, MD

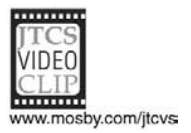

From the Department of Cardiothoracic Surgery, ${ }^{\text {a }}$ Stanford University School of Medicine, Stanford, Calif; the Laboratory of Cardiovascular Physiology and Biophysics, ${ }^{\text {b }}$ Palo Alto Medical Foundation Research Institute, Palo Alto, Calif; and the Department of Biomedical Engineering, Texas A\&M University, College Station, Tex.

Supported by grants HL-29589 and HL67025 from the National Heart, Lung, and Blood Institute (NHLBI). Drs Rodriguez, Langer, and Cheng were Carl and Leah McConnell Cardiovascular Surgical Research Fellows. Dr Rodriguez was supported by grant HL67025-01S1 from the NHLBI and was also a recipient of an American College of Surgeons Resident Research Scholarship Award. Dr Langer was supported by the Deutsche Akademie der Naturforscher Leopoldina. Dr Criscione was supported by grant $0265133 \mathrm{Y}$ from the American Heart Association.

Read at the Eighty-fourth Annual Meeting of The American Association for Thoracic Surgery, Toronto, Ontario, Canada, April 25-28, 2004.

Received for publication May 11, 2004; revisions received Sept 29, 2004; accepted for publication Nov 12, 2004.

Address for reprints: D. Craig Miller, MD, Department of Cardiothoracic Surgery, Falk Cardiovascular Research Center, Stanford University School of Medicine, Stanford, CA 94305-5247 (E-mail: dcm@stanford.edu).

J Thorac Cardiovasc Surg 2005;129: 791-803

$0022-5223 / \$ 30.00$

Copyright () 2005 by The American Association for Thoracic Surgery

doi:10.1016/j.jtcvs.2004.11.011

Objective: Helically oriented left ventricular fibers assemble into transmural sheets, which are important for wall-thickening mechanics: $15 \%$ fiber shortening results in $40 \%$ cross-fiber left ventricular wall thickening and a $60 \%$ ejection fraction through sheet extension, thickening, and shear. Normal cardiac microstructure and strains are optimized; deviations could result in apoptosis and deleterious matrix remodeling, which degenerates into global cardiomyopathy. We studied alterations in transmural strains adjacent to ischemic myocardium during acute midcircumflex occlusion.

Methods: Nine sheep had radiopaque markers implanted to measure left ventricular systolic fractional area shortening; 3 transmural bead columns were inserted into the midlateral wall for strain analysis. Three-dimensional marker coordinates were obtained with biplane videofluoroscopy before and during 70 seconds of ischemia. Systolic strains were quantified along circumferential, longitudinal, and radial axes $(\mathrm{n}=9)$ and were transformed into fiber-sheet coordinates by using quantitative microstructural measurements $(\mathrm{n}=5)$.

Results: A functional border was defined in the midlateral left ventricle; ischemia decreased posterolateral fractional area shortening, and anterolateral fractional area shortening increased. In this demarcation junction, subepicardial end-systolic radial wall thickening decreased $(0.16 \pm 0.08$ vs $0.11 \pm 0.06)$ and sheet-normal shear was abolished $(0.08 \pm 0.04$ vs $-0.01 \pm 0.03)$. Longitudinal shortening decreased in the subepicardium and midwall $(-0.05 \pm 0.04$ vs $\pm-0.01 \pm 0.06)$, but circumferentialradial shear increased at these depths $(0.04 \pm 0.04$ vs $0.11 \pm 0.05)$. Subendocardial fiber stretch occurred during early systole $(-0.01 \pm 0.03$ vs $0.02 \pm 0.03)$, and end-systolic fiber-sheet shear increased $(0.07 \pm 0.01$ vs $0.11 \pm 0.04$, all $P<.05)$.

Conclusions: Increased circumferential-radial shear and altered fiber-sheet strains reflect mechanical interactions between ischemic and nonischemic myocardium, which might be important in triggering remodeling processes that evolve into global ischemic cardiomyopathy.

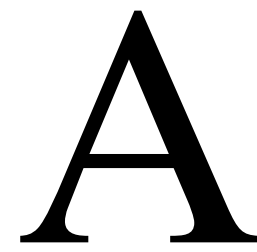

ttention has recently been focused on the importance of infarct extension caused by myocyte necrosis in the infarct border zone, despite normal border zone blood flow, in the pathogenesis of global ischemic cardiomyopathy after a single, initially welltolerated myocardial infarction (termed nonischemic infarct extension). ${ }^{1,2}$ Ratcliffe $^{2}$ proposed a hypothesis regarding the mechanisms underlying such extension on the basis of observations of abnormal circumferential lengthening strains in the border zone during early systolic isovolu- 
mic contraction in sheep. ${ }^{3}$ Such increased strain could trigger the production of reactive oxygen species, ${ }^{4,5}$ stimulate myocyte apoptosis, ${ }^{6-9}$ and activate matrix metalloproteinases, ${ }^{10-12}$ thereby causing subsequent collagen degradation and fibrosis that contribute to thinning and stretching of the border zone. $^{2}$

Although this mechanism is intellectually appealing, the alterations in transmural systolic strains and shears that underlie this hypothesis remain unknown. The left ventricle (LV) is composed of helically oriented fibers running parallel to the epicardial tangent plane that form a left-handed helix in the subepicardium and progress smoothly inward to a right-handed helix in the subendocardium. ${ }^{13}$ These fibers are interconnected by an extensive extracellular matrix to form branching transmural sheets approximately 4 cells thick, with extensive cleavage planes between the layers. ${ }^{14}$ Wall-thickening mechanics are complex, with $15 \%$ fiber shortening ${ }^{15}$ resulting in greater than $40 \%$ cross-fiber radial $\mathrm{LV}$ wall thickening and a $60 \% \mathrm{LV}$ ejection fraction through sheet extension, thickening, and shear. ${ }^{16}$ Normal cardiac microstructure and systolic strains are optimally coupled, and deviations could result in apoptosis and matrix remodeling. Conversely, it is possible that mechanical alterations result from, rather than trigger, the molecular remodeling processes.

Differences in mechanical properties between ischemic and nonischemic myocardium ${ }^{17}$ result in mechanical interactions at their junction. ${ }^{18}$ We hypothesized that such interaction increases shearing forces. Using 3-dimensional (3-D) transmural strain analysis ${ }^{17,19}$ and quantitative cardiac microstructure, ${ }^{16,20}$ we characterized the alterations in systolic strains adjacent to ischemic myocardium during acute midcircumflex occlusion with emphasis on fiber-sheet mechanics before molecular cascades could be established. These altered strains might be important in triggering remodeling processes that promote progression to global ischemic cardiomyopathy.

\section{Materials and Methods}

All animals received humane care in compliance with the "Principles of Laboratory Animal Care" formulated by the National Society for Medical Research and the "Guide for Care and Use of Laboratory Animals" prepared by the National Academy of Sciences and published by the National Institutes of Health (DHEW NIHG publication no. 85-23, revised 1985). This study was approved by the Stanford Medical Center Laboratory Research Animal Review committee and conducted according to Stanford University policy.

\section{Surgical Preparation}

Nine Dorsett-hybrid sheep $(73 \pm 12 \mathrm{~kg}[$ mean $\pm 1 \mathrm{SD}])$ were premedicated with ketamine $(25 \mathrm{mg} / \mathrm{kg}$ administered intramuscularly). Anesthesia was induced with sodium thiopental $(6.8 \mathrm{mg} / \mathrm{kg}$ administered intramuscularly) and maintained with inhalational isoflurane $(1.5 \%-2.2 \%)$. The heart was exposed through a left thoracotomy. A pneumatic occluder (In Vivo Metric Systems, Healdsburg, Calif) was placed around the circumflex coronary artery distal to the first obtuse-marginal branch.

Epicardial echocardiography identified a region of the midlateral LV wall between the papillary muscles at the equatorial level. After systolic wall depth was measured $(10 \pm 1 \mathrm{~mm}), 3$ transmural columns of 3 lead beads each ( 0.7 -mm diameter) were inserted and spaced evenly from the subendocardium to the subepicardium by using the Waldman method. ${ }^{19}$ The 3 bead columns were inserted into the midlateral wall $49 \% \pm 4 \%$ of the distance from base to apex, avoiding the papillary muscles by using a custom-designed needle trochar jig. Three $1.7-\mathrm{mm}$ beads were then sutured to the epicardial surface of each column (Figure 1, A).

Twelve radiopaque helical tantalum markers (outer diameter, $1.3 \mathrm{~mm}$; length, $1.5-3.0 \mathrm{~mm}$ ) were inserted in the subepicardium to silhouette the LV along 4 equally spaced longitudinal meridians defining the anterior, lateral, posterior, and septal LV walls at the basal, equatorial, and apical levels; a single marker was placed at the LV apex (nos. 1-13; Figure 1, $A$ ). The equatorial lateral marker (no. 12; Figure 1, $A$ ) was immediately basal to the beads, and an imaginary line connecting markers 11 and 12 bisected the transmural bead set (Figures 2 and 3). On cardiopulmonary bypass ( 84 \pm 12 minutes) with cardioplegic arrest (59 \pm 8 minutes), 8 additional tantalum markers were sutured equidistantly around the mitral annulus (nos. 14-21; Figure 1, A). Animals were weaned from cardiopulmonary bypass, and a micromanometer-tipped catheter (Millar SPC-500; Millar Instruments, Inc, Houston, Tex) was inserted through the LV apex. Correct marker placement was confirmed on necropsy.

\section{Experimental Protocol}

Data acquisition. The animals were immediately transferred to the catheterization laboratory and studied in an open-chest state with $1.5 \%$ to $2.2 \%$ isoflurane anesthesia. Three beat sequences of biplane videofluoroscopic and hemodynamic data were acquired in the right lateral decubitus position, with ventilation briefly arrested. All animals received intravenous magnesium (3 g), lidocaine (100 mg), and bretylium (50 mg) before baseline data acquisition as arrhythmia prophylaxis. After a 5-minute interval, the circumflex coronary artery was occluded for $68 \pm 30$ seconds, at which time ischemic data were acquired.

A Philips Optimus 2000 biplane Lateral ARC 2/poly DIAGNOST C2 system (Philips Medical Systems, Pleasanton, Calif) recorded videofluoroscopic images at $60 \mathrm{~Hz}$. Analog LV pressure and electrocardiographic signals were digitized simultaneously and recorded. Two-dimensional images from the 2 radiographic views were digitized ${ }^{21}$ and merged to yield 3-D coordinates of each radiopaque marker every $16.7 \mathrm{~ms}$, with an accuracy of $0.1 \pm 0.3 \mathrm{~mm}$ compared with known marker-tomarker 3-D lengths. ${ }^{22}$

In situ fixation. One gram of sodium pentothal was administered, and the heart was depolarized with $80 \mathrm{mEq}$ of intravenous potassium. LV pressure was adjusted to match in vivo LV enddiastolic pressure by using exsanguination and maintained constant throughout the in situ fixation process. The hearts were 


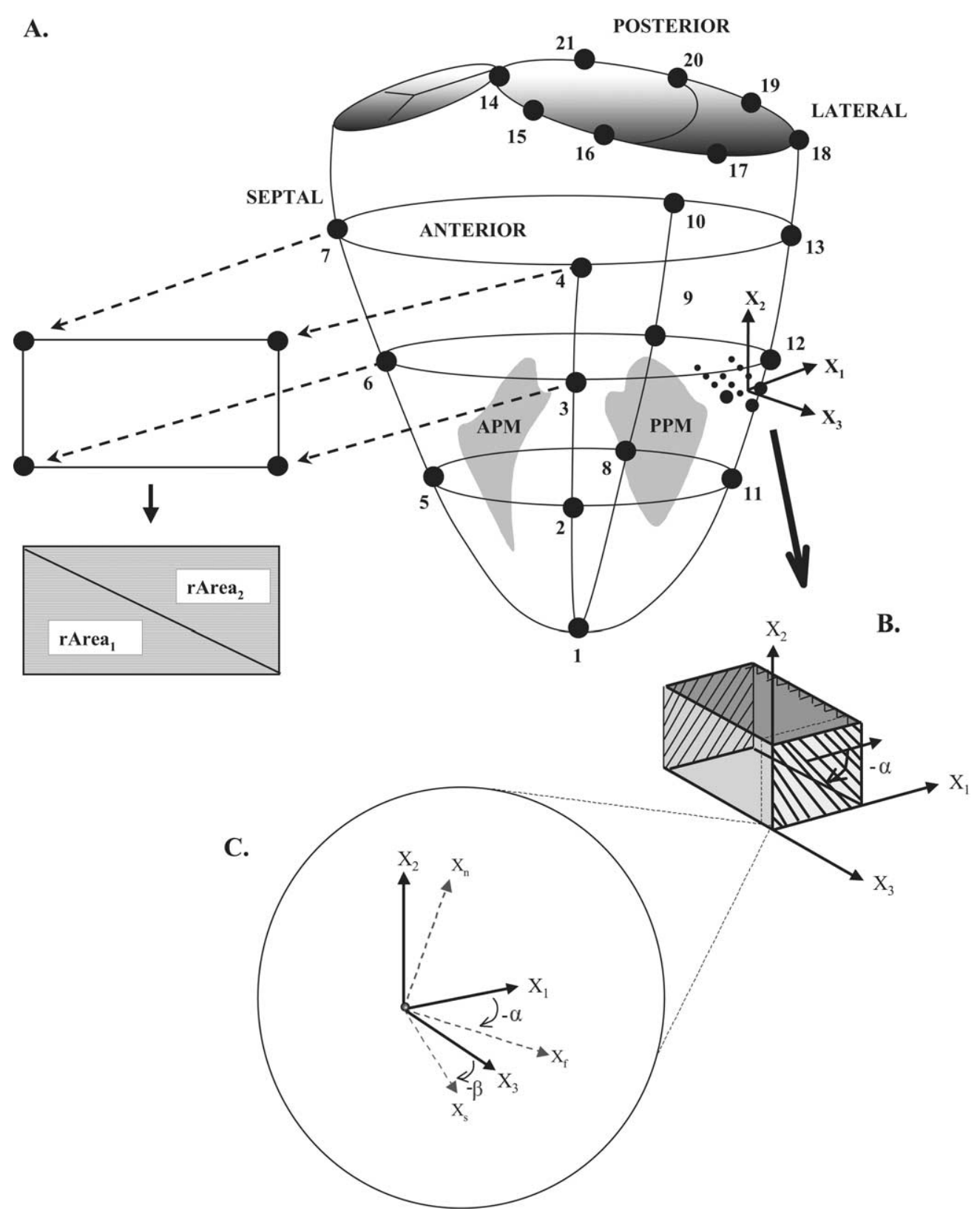

Figure 1. Radiopaque marker array, bead columns, and cardiac and fiber-sheet coordinate systems. A, Schematic depicting the global marker array (1-21) and the 3 transmural columns of radiopaque beads. Regional area defined by 4 epicardial markers was calculated as the sum of 2 triangular planar areas $\left(r A_{r e a}\right.$ and $\left.r A r e a_{2}\right)$. APM, Anterior papillary muscle; PPM, posterior papillary muscle. B, Transmural tissue block was excised from each heart, with the edges cut parallel to the local circumferential $\left(X_{1}\right)$, longitudinal $\left(X_{2}\right)$, and radial $\left(X_{3}\right)$ axes at the midlateral $L V$ wall. Transmural fiber angles $(\alpha)$ were measured from serial sections cut parallel to the $X_{1}-X_{2}$ plane. $C$, At a given transmural depth, measured fiber angles $(\alpha)$ and sheet angles $(\beta)$ are used to define local fiber-sheet coordinates with basis vectors of fiber axis $\left(X_{f}\right)$, sheet axis perpendicular to $X_{f}$ within sheet plane $\left(X_{s}\right)$, and axis normal to sheet plane $\left(X_{n}\right)$.

immediately fixed by using coronary perfusion with $600 \mathrm{~mL}$ of buffered glutaraldehyde (5\%), excised, and stored in $10 \%$ formalin. Correct marker placement was confirmed in all 9 hearts, but only 5 hearts were successfully fixed.

\section{Quantitative Transmural Microstructural} Measurements

To avoid the distortional effects of dehydration and shrinkage associated with embedding, microstructural measurements were 


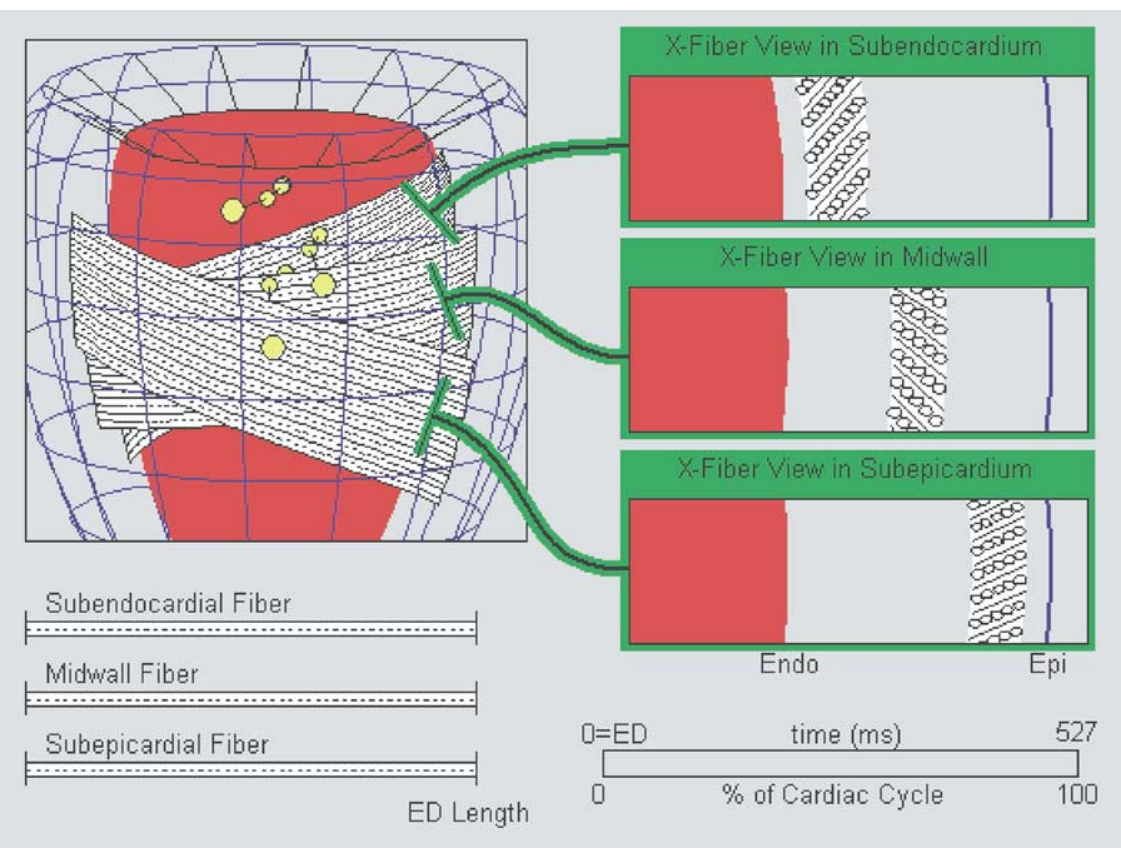

Figure 2. Three-dimensional animated, beating-heart model of transmural LV fiber and sheet geometry. A 3-D model depicting baseline LV motion was created from the LV markers, transmural bead sets, and quantitative microstructural measurements. The beads can be seen in the free wall of the blue wire mesh LV model. Measured fiber and sheet angles were incorporated into the model and are shown at the subepicardium (20\% wall depth), midwall ( $50 \%$ wall depth), and subendocardium ( $80 \%$ wall depth). Fiber angle was measured from sections parallel to the epicardium and progressed smoothly inward from a left-handed helix in the subepicardium to a right-handed helix in the subendocardium. Sheet angle was measured from cross-fiber sections and formed an accordion-like arrangement, being positive in the subepicardium, negative in the midwall, and positive in the subendocardium. Because data were only obtained from one site, an axis-symmetric heart model was created with motion that fit the bead measurements. By using cubic order interpolation in a cylindrical coordinate system coupled with $\mathrm{C1}$ continuous, cubic Hermite interpolation temporally, LV kinematics were defined with 49 degrees of freedom for the entire cardiac cycle. Fiber and sheet motion are shown throughout the cardiac cycle relative to ED. Sheet mechanics at 3 LV levels are shown at right. The 3 bars in the lower left corner show the temporal sequence and magnitude of fiber shortening in all 3 wall depths during the cardiac cycle. The bar in the lower right corner shows the cardiac cycle timing from ED to ED (0\%-100\%). Animated motion of this model can be viewed at www.mosby.com/jtcvs.

obtained with freshly fixed tissue. Fiber angle $(\alpha)$ was measured from sections cut parallel to the epicardium and defined as the angle subtended by $\mathrm{X}_{\mathrm{f}}$ and $\mathrm{X}_{1}$, with $\alpha$ being negative for a left-handed helix (Figure 1, $B$ and $C$ ). ${ }^{13,14}$ By using the method of Ashikaga and associates, ${ }^{20} 5$ angles representative of predominant sheet orientation were measured from cross-fiber frozen sections at $10 \%$ wall thickness intervals, and mean sheet angle $(\beta)$ was calculated for each transmural depth. Sheet angle $(\beta)$ was defined as the angle subtended by $X_{s}$ and $X_{3}$, with $\beta$ being negative if the sheet moves away from the LV base as one follows the sheet radially toward the epicardium (Figure $1, C) .{ }^{16}$

\section{Data Analysis}

Hemodynamics and cardiac cycle timing. End diastole (ED) was defined as the maximal second derivative of LV pressure, corresponding with the frame immediately before the upstroke of LV pressure. End systole (ES) was defined as the videofluoro- scopic frame before the time of peak negative LV rate of pressure decrease $\left(-\mathrm{dP}_{\mathrm{dt}} \mathrm{t}_{\max }\right)$. Instantaneous LV volume was calculated from LV and mitral annular markers by using multiple tetrahedra constructed from the marker coordinates and corrected for $\mathrm{LV}$ convexity. ${ }^{23}$

Epicardial LV volume calculated in this manner overestimates true chamber volume (incorporates an unknown amount of LV muscle mass), but changes in epicardial LV volume are accurate measurements of relative changes in chamber volume because LV muscle mass remains constant throughout the cardiac cycle. ${ }^{24}$

Regional LV systolic function. Ventricular systolic fractional area shortening (FAS) was used as an index of regional LV systolic function to determine the functional demarcation between ischemic and nonischemic myocardium. Each LV region defined by 4 subepicardial markers was divided into 2 triangular planar areas (Figure 1, $A$ ), except the apical regions, which were defined by triangular areas (Figure 3); regional area was then computed as 


\section{pre-Ischemia}

\section{Ischemia}

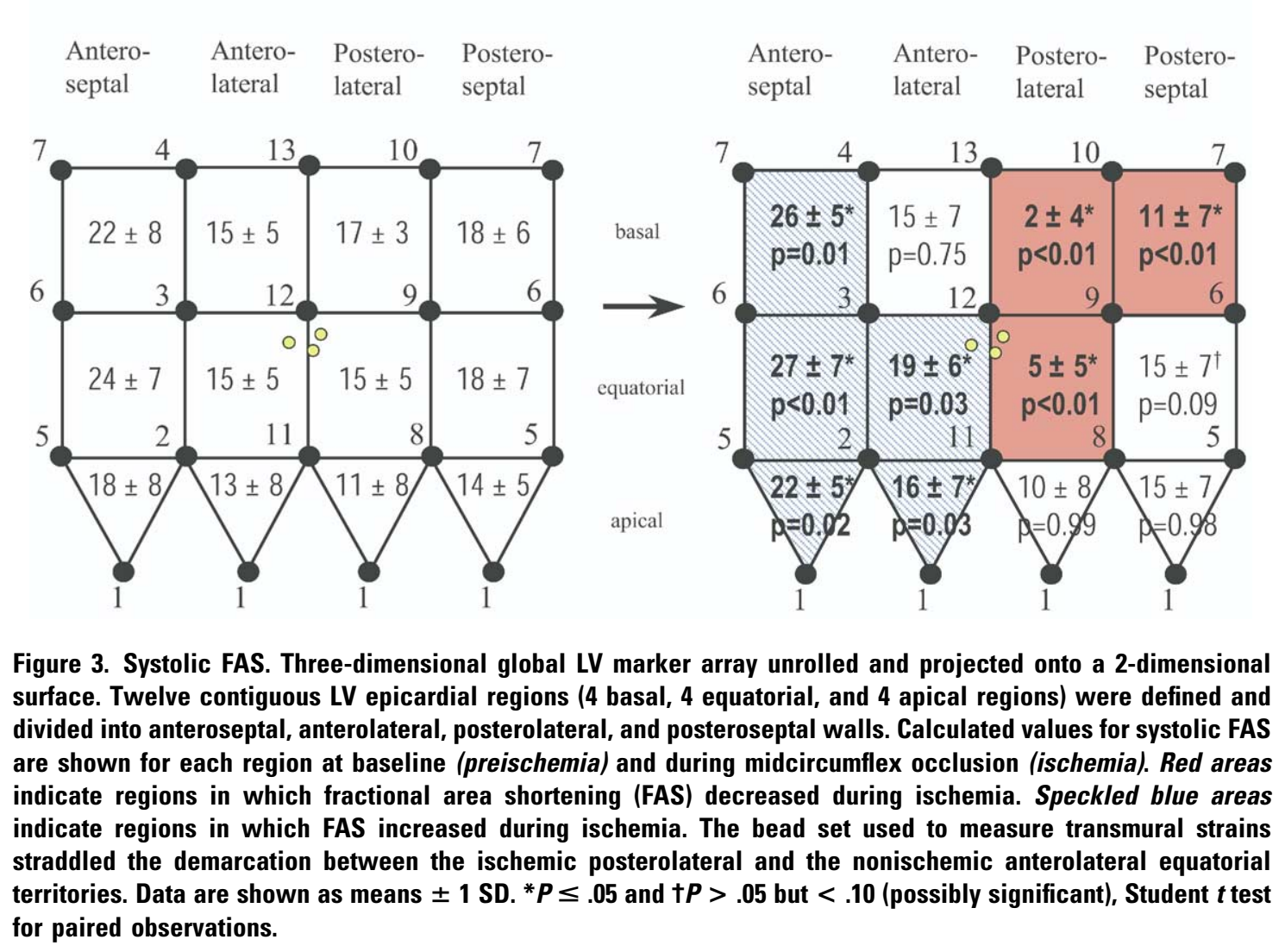

the sum of the areas of the triangles. Fractional change in systolic epicardial area was calculated as follows:

$$
F A S=100 \% \bullet\left(\left[\text { rArea }_{E D}-\text { rArea }_{E S}\right] / \text { rArea }_{E D}\right),
$$

where rArea $_{\mathrm{ED}}$ was the regional area at ED and $\mathrm{rArea}_{\mathrm{ES}}$ was the regional area at ES.

Transmural deformations and cardiac strain analysis. A local LV long axis was defined by using the centroid of the three 1.7-mm epicardial surface beads atop the columns and the apical marker (1; Figure 1, A), with local cardiac coordinates aligned with the circumferential $\left(\mathrm{X}_{1}\right)$, longitudinal $\left(\mathrm{X}_{2}\right)$, and radial $\left(\mathrm{X}_{3}\right)$ axes of the LV lateral wall. Because the local epicardial-tangent plane defines this coordinate system, wall curvature is taken into account. Strains were interpolated along the centroid of the bead columns at $1 \%$ increments of wall depth from the epicardium at ED. ${ }^{25}$ The most subendocardial bead was consistently at $90 \%$ of wall depth ( $9 \pm 1 \mathrm{~mm}$ from the epicardial surface), allowing for interpolation $(0 \%-90 \%)$ and extrapolation $(90 \%-100 \%)$ of strains through the entire LV wall. This method, which incorporates continuous data from 3 consecutive beats, builds on previous transmural bead strain analyses. ${ }^{16,17,19,20}$ The mean error of this method (developed by J.C.C.) for transmural continuous strain estimation is $1.02 \%$ (range, $0.04 \%-3.72 \%$ ) for the 6 tensor components (K. Kindberg, Linkoping, Sweden, unpublished data), as computed in cylindrical coordinates on a thick-walled incompress- ible cylinder undergoing inflation and stretch and torsional and transverse shear, as described by McCulloch and Omens. ${ }^{26}$

In local cardiac coordinates $\left(\mathrm{X}_{1}, \mathrm{X}_{2}\right.$, and $\left.\mathrm{X}_{3}\right)$, the 3 normal strain components measure myocardial stretch or shortening along the circumferential $\left(\mathrm{E}_{11}\right)$, longitudinal $\left(\mathrm{E}_{22}\right)$, and radial $\left(\mathrm{E}_{33}\right)$ cardiac axes. The 3 shear strains $\left(E_{12}, E_{13}\right.$, and $\left.E_{23}\right)$ represent angle changes between pairs of originally orthogonal coordinate axes. Transmural strains at 20\% (subepicardial), 50\% (mid), and $80 \%$ (subendocardial) wall depth were analyzed. Changes in bead positions at ED during ischemia (deformed configuration) were compared with those from ED at baseline (preischemia, reference configuration) to assess changes in local transmural myocardial geometry at ED (ie, end-diastolic strain). This describes changes in diastolic regional 3-D geometry associated with acute alterations in material properties and loading conditions. Systolic strains were calculated by comparing bead positions at ES (deformed configuration) with those at ED (reference configuration) for each data run ( 3 beats per run) before and during ischemia.

Transmural fiber-sheet strain analysis. In 5 sheep with successful fixation, transmural cardiac strains were transformed into fiber-sheet coordinates $\left(\mathrm{X}_{\mathrm{f}}, \mathrm{X}_{\mathrm{s}}\right.$, and $\mathrm{X}_{\mathrm{n}}$; Figure $\left.1, C\right)$ by using reported techniques. ${ }^{16,20}$ The resulting fiber-sheet strains include stretch or shortening along the fiber $\left(\mathrm{E}_{\mathrm{ff}}\right)$, sheet $\left(\mathrm{E}_{\mathrm{ss}}\right)$, and sheetnormal $\left(\mathrm{E}_{\mathrm{nn}}\right)$ directions and the 3 shear strains $\left(\mathrm{E}_{\mathrm{fs}}, \mathrm{E}_{\mathrm{fn}}\right.$, and $\mathrm{E}_{\mathrm{sn}}$, respectively). Whereas $\mathrm{E}_{\mathrm{fs}}$ describes shearing within the sheet 
TABLE 1. Hemodynamics

\begin{tabular}{lccl}
\hline \multicolumn{1}{c}{ Hemodynamics } & Preischemia & Ischemia & $P$ value \\
\hline $\mathrm{HR}\left(\min ^{-1}\right)$ & $101 \pm 15$ & $101 \pm 16$ & .37 \\
$\mathrm{dP} / \mathrm{dt}_{\max }(\mathrm{mm} \mathrm{Hg} / \mathrm{s})$ & $2310 \pm 691$ & $1600 \pm 541^{*}$ & .0005 \\
$\mathrm{EDV}(\mathrm{mL})$ & $213 \pm 50$ & $229 \pm 46^{*}$ & .02 \\
$\mathrm{ESV}(\mathrm{mL})$ & $156 \pm 51$ & $181 \pm 49^{*}$ & .0006 \\
$\mathrm{EDP}(\mathrm{mm} \mathrm{Hg})$ & $20 \pm 4$ & $24 \pm 6^{*}$ & .05 \\
$\mathrm{ESP}(\mathrm{mm} \mathrm{Hg})$ & $72 \pm 7$ & $56 \pm 8^{*}$ & .00003 \\
LVP $_{\text {max }}(\mathrm{mm} \mathrm{Hg})$ & $104 \pm 10$ & $86 \pm 13^{*}$ & .0001 \\
\hline
\end{tabular}

$H R$, Heart rate; $d P / d t_{\max }$ maximum positive rate of change of left ventricular pressure; $E D V$, end-diastolic volume; $E D P$, end-diastolic pressure; $\mathrm{LVP}_{\max }$, maximum left ventricular pressure.

$* P \leq .05$, ischemia versus preischemia, $t$ test for paired observations.

plane, the other 2 shear strains arise from relative sliding of adjacent myocardial laminae parallel to the fiber axis $\left(\mathrm{E}_{\mathrm{fn}}\right)$ or transverse to the fiber axis $\left(\mathrm{E}_{\mathrm{sn}}\right)$.

Statistical analysis. Hemodynamic and marker-derived data from 3 consecutive steady-state beats in sinus rhythm were time aligned at ED and averaged for each animal at baseline (preischemia) and during midcircumflex occlusion (ischemia). All data are reported as means $\pm 1 \mathrm{SD}$ unless otherwise specified. End-diastolic strains were compared with zero by using a 1-sample $t$ test. Changes in hemodynamics, FAS, and systolic strains were compared by using the Student $t$ test for paired observations.

\section{Results}

\section{Transmural Microstructure}

An animated 3-D video of a beating model of transmural LV fiber and sheet dynamic geometry throughout the cardiac cycle computed from the beads and markers is illustrated in Fig 2 (see electronic appendix). The microstructural configuration of the midlateral ovine heart wall at ED was characterized as follows. The helical fibers progressed inward smoothly from a left-handed helix in the subepicardium ( $20 \%$ wall depth, $\alpha=-26^{\circ} \pm 10^{\circ}$ ), to circumferential in the midwall $\left(50 \%\right.$ wall depth, $\left.\alpha=3^{\circ} \pm 10^{\circ}\right)$, to a right-handed helix in the subendocardium ( $80 \%$ wall depth, $\alpha=32^{\circ} \pm 14^{\circ}$ ); sheet angle $(\beta)$ measured $35^{\circ} \pm 7^{\circ}$ in the subepicardium, $-39^{\circ} \pm 21^{\circ}$ in the midwall, and $46^{\circ} \pm 19^{\circ}$ in the subendocardium, forming an accordion-like distribution.

\section{Systolic Fractional Area Shrinkage}

Table 1 lists the hemodynamic alterations during acute ischemia. Consistent with midcircumflex occlusion, ischemia caused decreased systolic FAS in the posterolateral and posteroseptal regions (Figure 3); conversely, FAS increased in the adjacent nonischemic anterolateral and remote anteroseptal regions. The transmural bead set straddled the junction between the ischemic posterolateral and nonischemic anterolateral myocardium (Figure 3).

\section{End-diastolic Strains}

Acute ischemia caused local LV lengthening and thinning along the demarcation between ischemic and nonischemic myocardium. Positive longitudinal strain $\left(\mathrm{E}_{22}\right.$, long-axis lengthening) was observed in both the subepicardium and midwall (both $0.02 \pm 0.03, P=.03$ ), along with negative transmural radial strain $\left(\mathrm{E}_{33}\right.$, wall thinning) in the subepicardium $(-0.03 \pm 0.03, P=.02)$, midwall $(-0.07 \pm 0.06$, $P=.006)$, and subendocardium $(-0.10 \pm 0.09, P=.01)$. Trends toward positive circumferential strain $\left(\mathrm{E}_{11}\right.$, circumferential stretch) were also observed in the subepicardium $(0.02 \pm 0.03, P=.09)$ and midwall $(0.03 \pm 0.05, P=.08)$. These end-diastolic strains are consistent with the abrupt increase in end-diastolic volume and end-diastolic pressure during acute ischemia (Table 1) causing LV dilatation, and wall thinning. In fiber-sheet coordinates, only subepicardial sheet-normal shear $\left(\mathrm{E}_{\mathrm{sn}} ;-0.01 \pm 0.01, P=.03\right)$ and midwall sheet-shortening strain $\left(\mathrm{E}_{\mathrm{ss}} ;-0.04 \pm 0.03, P=\right.$ .05 ) changed, both of which were consistent with transmural radial wall thinning.

\section{Baseline Systolic Strains}

Table 2 lists the cardiac and fiber-sheet transmural systolic strains from ED to ES. At baseline (preischemia), transmural circumferential $\left(\mathrm{E}_{11}\right)$ and longitudinal $\left(\mathrm{E}_{22}\right)$ shortening occurred. Transmural fiber strains $\left(\mathrm{E}_{\mathrm{ff}}\right)$ were similar, and no transmural gradient in $\mathrm{E}_{33}$ was detected. Consistent with wall-thickening mechanics, transmural sheet extension (increased $\left.\mathrm{E}_{\mathrm{ss}}\right)$ occurred, and sheet-normal shear $\left(\mathrm{E}_{\mathrm{sn}}\right)$ alternated at each wall depth (positive in the subepicardium, negative in the midwall, and positive in the subendocardium), reflecting the accordion-like distribution of sheets in this region (Figure 2).

\section{Systolic Strains Adjacent to Ischemic Myocardium}

All subepicardial 3-D cardiac strains and subendocardial 3-D fiber-sheet strains are shown throughout the cardiac cycle in Figures 4 and 5, respectively, to illustrate the key findings of this study. During ischemia, subepicardial longitudinal shortening $\left(\mathrm{E}_{22}\right)$ and radial wall thickening $\left(\mathrm{E}_{33}\right)$ decreased, but circumferential-radial shear $\left(\mathrm{E}_{13}\right)$ increased (Figure 4). No change in transmural end-systolic circumferential strain $\left(\mathrm{E}_{11}\right)$ was observed (Table 2). During systole, however, subepicardial circumferential stretch occurred at midejection (Figure 4, upper left panel). In fiber-sheet coordinates, subepicardial sheet thinning $\left(\mathrm{E}_{\mathrm{nn}}\right)$ increased, and sheet-normal shear $\left(\mathrm{E}_{\mathrm{sn}}\right)$ disappeared (Table 2).

In the midwall and subepicardium, longitudinal shortening $\left(\mathrm{E}_{22}\right)$ decreased and circumferential-radial shear $\left(\mathrm{E}_{13}\right)$ increased during ischemia (Table 2). A trend toward increased midwall longitudinal-radial shear $\left(\mathrm{E}_{23}\right)$ was present. In fiber-sheet coordinates midwall sheet thickening $\left(\mathrm{E}_{\mathrm{nn}}\right)$ increased (Table 2). A trend toward decreased midwall 
TABLE 2. Transmural systolic strains in the functional ischemic border zone

\begin{tabular}{|c|c|c|c|}
\hline & Preischemia & Ischemia & $P$ value \\
\hline \multicolumn{4}{|l|}{ Cardiac strains $(n=9)$} \\
\hline \multicolumn{4}{|l|}{ Subepicardium } \\
\hline Circumferential strain $\left(E_{11}\right)$ & $-0.05 \pm 0.06$ & $-0.02 \pm 0.04$ & .26 \\
\hline Longitudinal strain $\left(E_{22}\right)$ & $-0.05 \pm 0.04$ & $-0.01 \pm 0.05^{*}$ & .02 \\
\hline Radial strain $\left(E_{33}\right)$ & $0.16 \pm 0.08$ & $0.11 \pm 0.06^{*}$ & .02 \\
\hline Circumferential-Iongitudinal shear $\left(\mathrm{E}_{12}\right)$ & $0.02 \pm 0.04$ & $0.03 \pm 0.04$ & .37 \\
\hline Longitudinal-radial shear $\left(E_{23}\right)$ & $0.03 \pm 0.08$ & $0.07 \pm 0.05$ & .14 \\
\hline Circumferential-radial shear $\left(\mathrm{E}_{13}\right)$ & $0.04 \pm 0.04$ & $0.11 \pm 0.05^{*}$ & .002 \\
\hline \multicolumn{4}{|l|}{ Midwall } \\
\hline Circumferential strain $\left(\mathrm{E}_{11}\right)$ & $-0.06 \pm 0.07$ & $-0.04 \pm 0.06$ & .44 \\
\hline Longitudinal strain $\left(E_{22}\right)$ & $-0.05 \pm 0.04$ & $-0.01 \pm 0.06^{*}$ & .03 \\
\hline Radial strain $\left(E_{33}\right)$ & $0.15 \pm 0.07$ & $0.14 \pm 0.10$ & .82 \\
\hline Circumferential-longitudinal shear $\left(E_{12}\right)$ & $0.01 \pm 0.05$ & $0.03 \pm 0.05$ & .34 \\
\hline Longitudinal-radial shear $\left(\mathrm{E}_{23}\right)$ & $0.04 \pm 0.07$ & $0.09 \pm 0.06 \dagger$ & .07 \\
\hline Circumferential-radial shear $\left(\mathrm{E}_{13}\right)$ & $0.03 \pm 0.04$ & $0.07 \pm 0.04^{*}$ & .0004 \\
\hline \multicolumn{4}{|l|}{ Subendocardium } \\
\hline Circumferential strain $\left(\mathrm{E}_{11}\right)$ & $-0.11 \pm 0.07$ & $-0.07 \pm 0.07$ & .13 \\
\hline Longitudinal strain $\left(E_{22}\right)$ & $-0.04 \pm 0.05$ & $-0.02 \pm 0.08$ & .28 \\
\hline Radial strain $\left(\mathrm{E}_{33}\right)$ & $0.16 \pm 0.12$ & $0.21 \pm 0.19$ & .47 \\
\hline Circumferential-longitudinal shear $\left(\mathrm{E}_{12}\right)$ & $0.04 \pm 0.05$ & $0.04 \pm 0.05$ & .93 \\
\hline Longitudinal-radial shear $\left(\mathrm{E}_{23}\right)$ & $0.06 \pm 0.14$ & $0.12 \pm 0.11$ & .14 \\
\hline Circumferential-radial shear $\left(\mathrm{E}_{13}\right)$ & $0.03 \pm 0.07$ & $0.05 \pm 0.08$ & .35 \\
\hline \multicolumn{4}{|l|}{ Fiber-sheet strains ( $n=5$ ) } \\
\hline \multicolumn{4}{|l|}{ Subepicardium } \\
\hline Fiber strain $\left(E_{\mathrm{ff}}\right)$ & $-0.06 \pm 0.08$ & $-0.03 \pm 0.05$ & .42 \\
\hline Sheet strain $\left(\mathrm{E}_{\mathrm{ss}}\right)$ & $0.15 \pm 0.12$ & $0.17 \pm 0.08$ & .58 \\
\hline Normal strain $\left(\mathrm{E}_{\mathrm{nn}}\right)$ & $-0.01 \pm 0.08$ & $-0.06 \pm 0.05^{*}$ & .03 \\
\hline Fiber-sheet shear $\left(\mathrm{E}_{\mathrm{fs}}\right)$ & $0.03 \pm 0.08$ & $0.07 \pm 0.07$ & .22 \\
\hline Fiber-normal shear $\left(\mathrm{E}_{\mathrm{fn}}\right)$ & $0.00 \pm 0.04$ & $0.02 \pm 0.01$ & .25 \\
\hline Sheet-normal shear $\left(\mathrm{E}_{\mathrm{sn}}\right)$ & $0.08 \pm 0.04$ & $-0.01 \pm 0.03^{*}$ & .0002 \\
\hline \multicolumn{4}{|l|}{ Midwall } \\
\hline Fiber strain $\left(\mathrm{E}_{\mathrm{ff}}\right)$ & $-0.07 \pm 0.08$ & $-0.02 \pm 0.07$ & .30 \\
\hline Sheet strain $\left(\mathrm{E}_{\mathrm{ss}}\right)$ & $0.05 \pm 0.10$ & $-0.02 \pm 0.07 \dagger$ & .07 \\
\hline Normal strain $\left(\mathrm{E}_{\mathrm{nn}}\right)$ & $0.05 \pm 0.10$ & $0.11 \pm 0.08^{*}$ & .02 \\
\hline Fiber-sheet shear $\left(\mathrm{E}_{\mathrm{fs}}\right)$ & $0.01 \pm 0.05$ & $0.05 \pm 0.06 \dagger$ & .09 \\
\hline Fiber-normal shear $\left(\mathrm{E}_{\mathrm{fn}}\right)$ & $-0.02 \pm 0.05$ & $-0.05 \pm 0.02$ & .20 \\
\hline Sheet-normal shear $\left(\mathrm{E}_{\mathrm{sn}}\right)$ & $-0.10 \pm 0.09$ & $-0.07 \pm 0.08$ & .37 \\
\hline \multicolumn{4}{|l|}{ Subendocardium } \\
\hline Fiber strain $\left(\mathrm{E}_{\mathrm{ff}}\right)$ & $-0.06 \pm 0.06$ & $-0.004 \pm 0.07^{*}$ & .02 \\
\hline Sheet strain $\left(\mathrm{E}_{\mathrm{ss}}\right)$ & $0.08 \pm 0.30$ & $0.13 \pm 0.17$ & .63 \\
\hline Normal strain $\left(\mathrm{E}_{\mathrm{nn}}\right)$ & $0.01 \pm 0.15$ & $-0.03 \pm 0.20$ & .22 \\
\hline Fiber-sheet shear $\left(E_{\mathrm{fs}}\right)$ & $0.07 \pm 0.01$ & $0.11 \pm 0.04^{*}$ & .04 \\
\hline Fiber-normal shear $\left(\mathrm{E}_{\mathrm{fn}}\right)$ & $0.00 \pm 0.06$ & $0.06 \pm 0.06$ & .11 \\
\hline Sheet-normal shear $\left(\mathrm{E}_{\mathrm{sn}}\right)$ & $0.12 \pm 0.06$ & $0.07 \pm 0.11$ & .40 \\
\hline
\end{tabular}

$* P \leq .05$, ischemia versus preischemia, $t$ test for paired observations.

$\dagger P>.05$ but $<.10$, ischemia versus preischemia, $t$ test for paired observations; possibly significant.

sheet extension $\left(\mathrm{E}_{\mathrm{ss}}\right)$ and increased fiber-sheet shear $\left(\mathrm{E}_{\mathrm{fs}}\right)$ was observed.

Interestingly, no changes in subendocardial cardiac strains were seen, but significant alterations in subendocardial fiber-sheet strains occurred. Because of fiber stretch during early systole (Figure 5, lower left panel), fiber short- ening $\left(\mathrm{E}_{\mathrm{ff}}\right)$ at $\mathrm{ES}$ was abolished (Table 2); moreover, fibersheet shear $\left(\mathrm{E}_{\mathrm{fs}}\right)$ increased during ischemia.

In summary, these data demonstrated acute mechanical interactions in the junctional zone, which abruptly resulted in fiber stretching during systole with increased circumferential-radial and fiber-sheet shear strain. 


\section{NORMAL STRAINS}
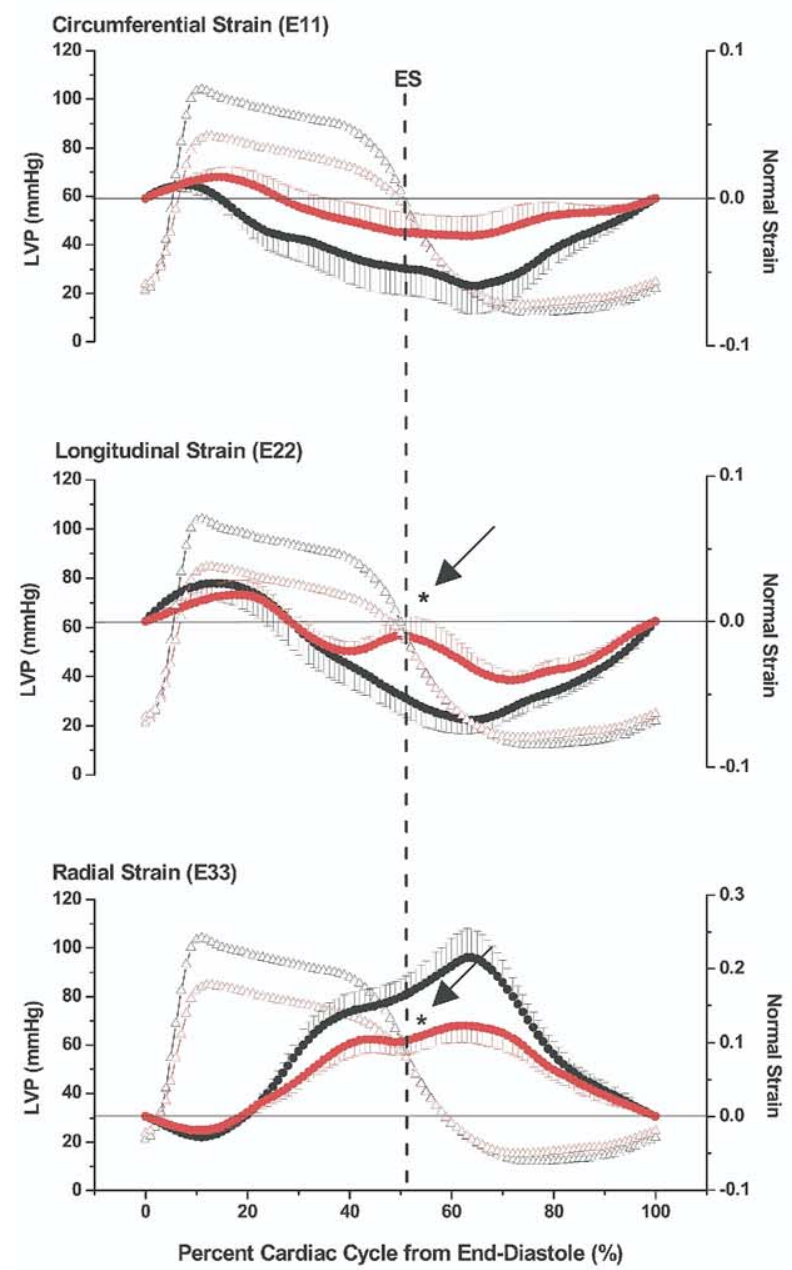

\section{SHEAR STRAINS}

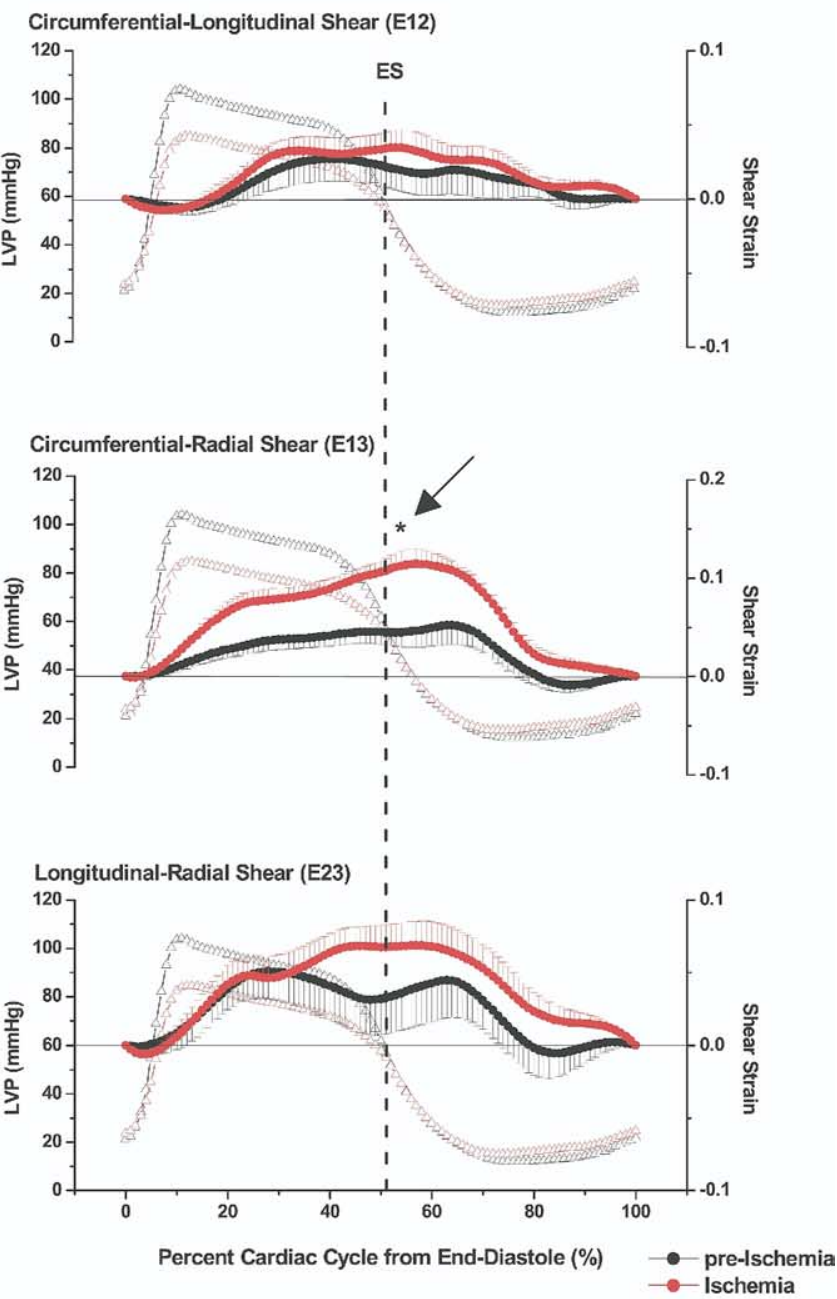

Figure 4. Systolic cardiac strains in the subepicardium. LV pressure (LVP, in $\mathbf{m m ~} \mathrm{Hg}$ ) is on the left ordinate (open triangles), with cardiac normal strains $\left(\mathrm{E}_{11}, \mathrm{E}_{22}\right.$, and $\left.\mathrm{E}_{33}\right)$ and shear strains $\left(\mathrm{E}_{12}, \mathrm{E}_{13}\right.$, and $\left.\mathrm{E}_{23}\right)$ in the functional border subepicardium (20\% wall depth) on the right ordinate (full circles) as a function of the percentage cardiac cycle from ED on the abscissa. Data are shown during control (preischemia, black symbols) and 70 seconds of ischemia (ischemia, red symbols) as mean \pm 1 SEM for 9 animals ( 3 beats each), with cardiac cycle lengths normalized and adjusted with cubic Hermite interpolation in time by using 5 equally spaced time nodes in the cardiac cycle. The dashed line denotes the time of ES when strains were compared. Arrows point to significant changes at ES. ${ }^{*} \boldsymbol{P}<$ .05 , Student $t$ test for paired observations.

\section{Discussion}

This experiment revealed substantial alterations in transmural cardiac and fiber-sheet systolic strains adjacent to ischemic myocardium during acute midcircumflex occlusion. These changes occurred after only 70 seconds of ischemia, probably before any molecular processes could be established. Increased circumferential-radial LV wall shear during systole with increased fiber-sheet shear strain reflects the direct mechanical interaction between ischemic and nonischemic myocardium. Significant systolic circumferential LV and fiber stretch also occurred. Such deviation from normal strain patterns (either increased or decreased) results in the production of reactive oxygen species, ${ }^{4,5}$ which stimulate myocyte apoptosis ${ }^{6-9}$ and activate matrix metalloproteinases. ${ }^{10-12}$ These alterations in fiber-sheet strains might underlie nonischemic infarct extension, as proposed by Ratcliffe. ${ }^{2}$

Alterations in 3-D cardiac strains in the ischemic region have been described, ${ }^{17}$ and previous studies have also measured 2-dimensional epicardial strain gradients across the perfusion boundary during acute myocardial ischemia. ${ }^{18}$ 


\section{NORMAL STRAINS}

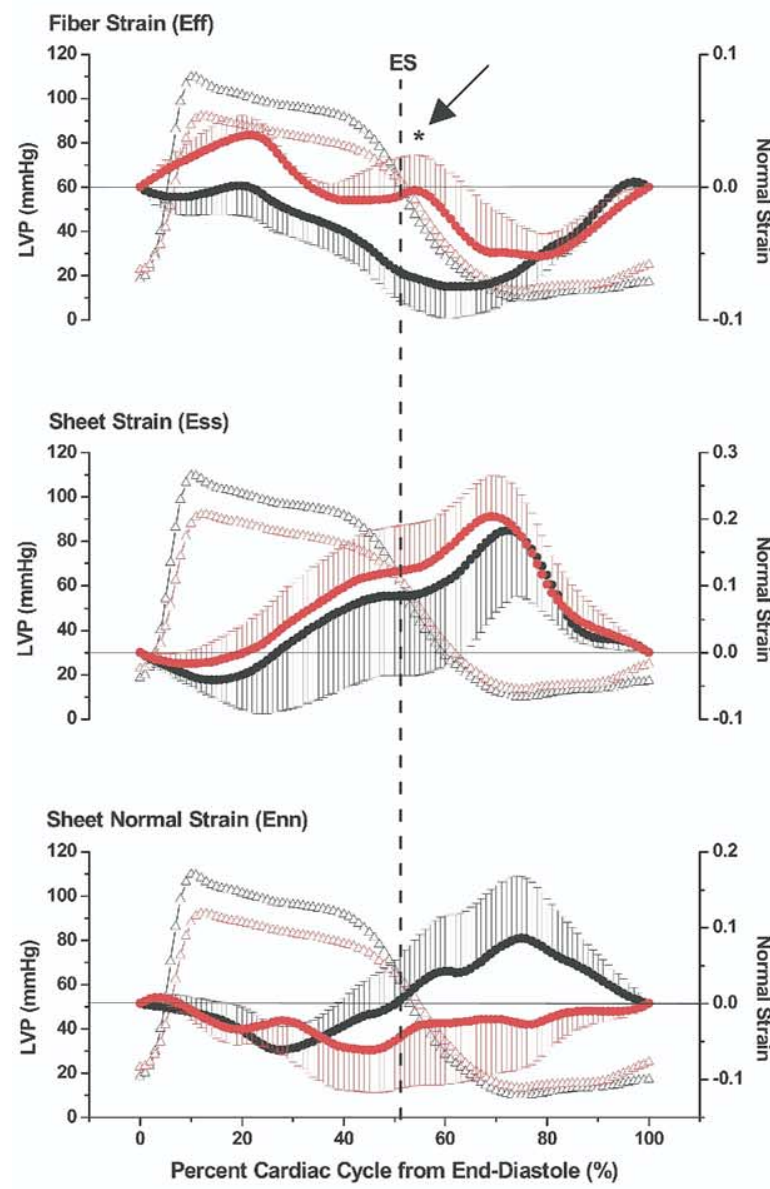

\section{SHEAR STRAINS}
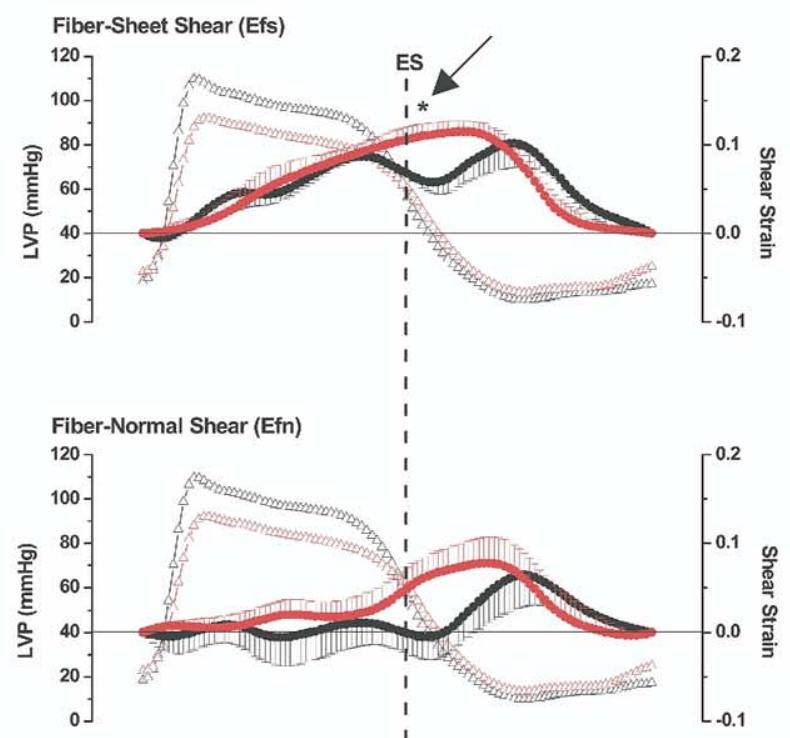

Figure 5. Systolic fiber-sheet strains in the subendocardium. LV pressure (LVP, in $\mathrm{mm} \mathrm{Hg}$ ) is on the left ordinate (open triangles), with normal strains $\left(\mathrm{E}_{\mathrm{ff}}, \mathrm{E}_{\mathrm{ss}}\right.$, and $\left.\mathrm{E}_{\mathrm{nn}}\right)$ and shear strains $\left(\mathrm{E}_{\mathrm{fs}}, \mathrm{E}_{\mathrm{fn}}\right.$, and $\left.\mathrm{E}_{\mathrm{sn}}\right)$ in the functional border subendocardium $(80 \%$ wall depth) on the right ordinate (full circles) as a function of the percentage cardiac cycle from ED on the abscissa. Data are shown during control (preischemia, black symbols) and 70 seconds of ischemia (ischemia, red symbols) as the mean \pm 1 SEM for 5 animals (3 beats each), with cardiac cycle lengths normalized and adjusted with cubic Hermite interpolation in time by using 5 equally spaced time nodes in the cardiac cycle. The dashed line denotes the time of ES when strains were compared. Arrows point to significant changes at ES. ${ }^{*} P<.05$, Student $t$ test for paired observations.

Moulton and colleagues ${ }^{3}$ used magnetic resonance imaging tissue radiofrequency tagging and quantitative fiber measurements in sheep to assess 2-dimensional midwall strains in the border zone after infarction. Characterization of transmural changes in 3-D myocardial strains adjacent to ischemic myocardium, however, is nonexistent. Incomplete knowledge of cardiac fibrous and laminar (sheet) microstructure also hinders more complete finite element modeling of wall-thickening mechanics. Because fiber architecture and integrity are initially preserved in the border zone, ${ }^{3}$ analysis of deformations in this region after infarction should include analysis of fiber-sheet strains.
When conceptualizing myocardial deformations, it is convenient to think in terms of cardiac coordinates (ie, circumferential $\left[\mathrm{X}_{1}\right]$, longitudinal $\left[\mathrm{X}_{2}\right]$, and radial $\left[\mathrm{X}_{3}\right]$ ), which characterize circumferential shortening/stretch $\left(\mathrm{E}_{11}\right.$ strain), longitudinal shortening/stretch $\left(\mathrm{E}_{22}\right.$ strain), and radial wall thickening/thinning ( $\mathrm{E}_{33}$ strain; Figure 2). Cardiac strains are relatively intuitive to understand because they correspond to normal clinical measures of cardiac function and reflect the contraction (or stretching) of the LV myocardium in the LV wall. The 3 shear strains $\left(\mathrm{E}_{12}, \mathrm{E}_{13}\right.$, and $\left.\mathrm{E}_{23}\right)$ represent angle changes between pairs of the originally orthogonal coordinate axes. 
During ischemia, decreased subepicardial and midwall longitudinal shortening $\left(E_{22}\right)$ was seen at the demarcation between ischemic and nonischemic myocardium (Table 2), which is similar to findings from Van Leuven and coworkers. ${ }^{18}$ In addition, we observed systolic subepicardial circumferential stretch $\left(\mathrm{E}_{11}\right.$ strain) during ischemia (Figure 4, upper left panel), which reached statistical significance at midejection $(-0.02 \pm 0.04$ [baseline] vs $0.01 \pm 0.03$ [ischemia], $P=.03)$. Such systolic circumferential stretching is consistent with the findings of Moulton and colleagues ${ }^{3}$ showing midwall circumferential stretch in the infarct border zone during isovolumic contraction.

Although decreased subepicardial and midwall longitudinal shortening might reflect decreased systolic function in the junction between ischemic and nonischemic myocardium, they differ from the transmural myocardial deformations measured within the ischemic region itself. Using a similar radiopaque bead column technique, Villarreal and associates ${ }^{17}$ observed transmural circumferential and longitudinal stretching at ES along with radial wall thinning in the ischemic region; in contrast, we only observed decreased subepicardial radial wall thickening and longitudinal shortening (Table 2). Although some subepicardial circumferential stretch occurred at midejection (Figure 4, upper left panel), no change in transmural circumferential shortening was observed at ES (Table 2). In ischemic myocardium, transmural circumferential-longitudinal $\left(\mathrm{E}_{12}\right)$, circumferential-radial $\left(\mathrm{E}_{13}\right)$, and longitudinal-radial $\left(\mathrm{E}_{23}\right)$ shears all reverse and become negative. ${ }^{17}$ In our study, however, subepicardial and midwall circumferential-radial shear and midwall longitudinal-radial shear increased adjacent to the ischemic myocardium (Table 2). The direction of increased circumferential-radial $\left(\mathrm{E}_{13}\right)$ shear strain was consistent with the beads' location in relation to the nonischemic and ischemic myocardium and likely reflects mechanical interaction between these regions (Figures 2 and 3).

At a more fundamental level, the effects of myocardial deformations must be interpreted within the context of their direct effects on cardiomyocytes because it is perturbations of cardiomyocyte strain patterns that trigger apoptosis ${ }^{5}$ and matrix remodeling. ${ }^{12}$ Because fibers are oriented in circumferential-longitudinal planes with their angle $(\alpha)$ varying continuously through the LV wall, ${ }^{13}$ measurements of circumferential, longitudinal, and especially radial cardiac strains only indirectly reflect cardiomyocyte deformation.

Morphologic studies of the LV myocardium demonstrating a syncytium of cardiomyocytes arranged into branching laminar sheets ${ }^{14}$ have facilitated understanding of how contraction of the circumferentially oriented fibers could be transformed into radial wall thickening through laminar (sheet) extension, shear, and thickening. ${ }^{16}$ To comprehend better the effect of strain alterations at the cardiomyocyte level, measurements of 3-D transmural cardiac strains were transformed to 3-D fiber-sheet axes by using the quantitative microstructural measurements (see Figure 2 video). During ischemia, subepicardial sheet thinning strain $\left(E_{n n}\right)$ increased, and sheet-normal shear $\left(\mathrm{E}_{\mathrm{sn}}\right)$ was abolished. This loss of subepicardial sheet-normal shear reflects the decrease in subepicardial radial wall thickening $\left(\mathrm{E}_{33}\right)$ (Table 2 and Figure 4, lower left panel). In the midwall sheet extension strain $\left(\mathrm{E}_{\mathrm{ss}}\right)$ decreased, sheet thickening strain $\left(\mathrm{E}_{\mathrm{nn}}\right)$ increased, and fiber-sheet shear $\left(\mathrm{E}_{\mathrm{fs}}\right)$ increased. Fiber-sheet shear strain also increased in the subendocardium (Figure 5, upper right panel), and the direction of increased midwall and subepicardial fiber-sheet shear was consistent with the junctional location of the bead columns. Such increased fiber-sheet shear strain reflects mechanical interaction between these regions at the microstructural level.

Subendocardial end-systolic fiber-shortening strain $\left(\mathrm{E}_{\mathrm{ff}}\right)$ was abolished; that is, the fibers failed to shorten from their original end-diastolic length, which might reflect either decreased fiber function or increased fiber load, which limits total fiber shortening. Accordingly, increased subendocardial fiber stretch $(-0.01 \pm 0.03$ [baseline] vs $0.02 \pm 0.03$ [ischemia], $P=.04$ ) was observed during early systole and persisted through midejection $(-0.003 \pm 0.06$ [baseline] vs $0.04 \pm 0.02$ [ischemia], $P=.09$; Figure 5, upper left panel). Systolic fiber stretch in this region during ischemia might reflect increased fiber load caused by the hyperkinetic FAS in the adjacent anterolateral and remote anteroseptal regions (Figure 3). Such fiber stretch is also consistent with the findings of Moulton and colleagues. ${ }^{3}$ Because fibers in the midwall run circumferentially, the midwall circumferential wall stretch they observed during isovolumic contraction also reflects midwall fiber stretch.

We demonstrated significant alterations in transmural systolic strains adjacent to ischemic myocardium during acute midcircumflex occlusion. Although no molecular data were obtained, these findings emphasize the need for further research regarding the cellular remodeling processes triggered by mechanical strain alterations, which might be important in the evolution into global ischemic cardiomyopathy. Advances in magnetic resonance imaging diffusion tensor imaging can now be used to evaluate the structure and function of LV myocardial fibers and sheets in human subjects. ${ }^{27}$ Such enhanced understanding of the myocardial fibrous and laminar architecture and transmural LV strains should enhance finite element analysis models of LV wall mechanics and possibly contribute to the design of better surgical remodeling procedures to restore normal ventricular strain patterns in patients with ischemic cardiomyopathy. ${ }^{11,28,29}$

\section{Study Limitations}

These data were obtained in an acute, open-chest setting in normal sheep hearts immediately after a complex surgical 
procedure during acute myocardial ischemia, and therefore direct extrapolation of these findings to patients with chronic ischemic cardiomyopathy is perilous. Chronic postinfarction remodeling in the border zone and remote myocardial regions in experimental animals and human subjects requires further investigation. Fiber-sheet dynamics observed in open-chest, anesthetized sheep might not accurately reflect cardiac mechanics in closed-chest, awake animals or human subjects. There is potential concern regarding the effects of tissue injury on measured strains caused by the insertion of the radiopaque beads or prior aortic crossclamping. The myocardium might have been stunned after cardioplegic arrest, but our experimental design allowed for sequential comparisons between baseline, preischemic, and ischemic conditions without confounding factors between study conditions. The measured average circumferential strain $\left(E_{11}\right)$ across the entire $L V$ wall was -0.073 , which is similar to $E_{11}$ strains calculated by us in the same region in a group of closed-chest, anesthetized sham animals 1 week after bead-set marker implantation without CPB (average circumferential $\mathrm{E}_{11}=-0.086$, unpublished data) and consistent with previously reported $\mathrm{E}_{11}$ strains $(0.093$ and -0.12 , respectively) derived in canine anterior LV wall transmural bead studies ${ }^{17,19}$ in the canine anterior LV wall. Fiber-sheet dynamics differ regionally because of substantial regional variations in fiber and sheet distributions ${ }^{13,14,16}$ and different contribution to wall thickening $^{27}$; our data represent fiber-sheet mechanics only in the midlateral LV wall. Species differences (ovine vs human) must also be considered because little is known about the species variation of fiber-sheet structures.

The need for immediate glutaraldehyde fixation for quantitative microstructural measurements precluded assessment of tissue perfusion; however, FAS defined the junctional region functionally. All bead sets and markers were placed by a single surgeon (F.R.) to minimize variability. Because the beads straddled the junctional zone (Figure 3), they might have been located in a hybrid locus of ischemic and nonischemic myocardium. Although additional bead sets in the ischemic and nonischemic myocardial regions would have added interesting information, such was not possible because of technical limitations.

We appreciate the technical assistance provided by Mary $\mathrm{K}$. Zasio, BA; Carol W. Mead, BA; Maggie Brophy, AS; Katha Gazda, BA; and Mark Grisedale, DVM, and the collaboration and support of James Covell, MD.

\section{References}

1. Jackson BM, Gorman JH, Moainie SL, Guy TS, Narula N, Narula J, et al. Extension of borderzone myocardium in postinfarction dilated cardiomyopathy. J Am Coll Cardiol. 2002;40:1160-7.

2. Ratcliffe MB. Non-ischemic infarct extension. J Am Coll Cardiol. 2002;40:1168-71.

3. Moulton MJ, Downing SW, Creswell LL, Fishman DS, Amsterdam DM, Szabo BA, et al. Mechanical dysfunction in the border zone of an ovine model of left ventricular aneurysm. Ann Thorac Surg. 1995;60:986-97.

4. Pimentel DR, Amin JK, Xiao L, Miller T, Viereck J, Oliver-Krasinski $\mathrm{J}$, et al. Reactive oxygen species mediate amplitude-dependent hypertrophic and apoptotic responses to mechanical stretch in cardiac myocytes. Circ Res. 2001;89:453-60.

5. Cheng W, Li B, Kajstura J, Li P, Wolin MS, Sonnenblick EH, et al. Stretch-induced programmed myocyte cell death. J Clin Invest. 1995; 96:2247-59.

6. Kang PM, Izumo S. Apoptosis and heart failure: a critical review of the literature. Circ Res. 2000;86:1107-13.

7. Saraste A, Pulkki K, Kallajoki M, Henriksen K, Parvinen M, VoipioPulkki LM. Apoptosis in human acute myocardial infarction. Circulation. 1997;95:320-3.

8. Olivetti G, Abbi R, Quaini F, Kajstura J, Cheng W, Nitahara JA, et al. Apoptosis in the failing human heart. N Engl J Med. 1997;336:113141.

9. Cheng W, Kajstura J, Nitahara JA, Li B, Reiss K, Liu Y, et al. Programmed myocyte cell death affects the viable myocardium after infarction in rats. Exp Cell Res. 1996;226:316-27.

10. Wilson EM, Moainie SL, Baskin JM, Lowry AS, Deschamps AM, Mukherjee R, et al. Region- and type-specific induction of matrix metalloproteinases in post-myocardial infarction remodeling. Circulation. 2003;107:2857-63.

11. Bowen FW, Jones SC, Narula N, John Sutton MG, Plappert T, Edmunds LH Jr, et al. Restraining acute infarct expansion decreases collagenase activity in borderzone myocardium. Ann Thorac Surg. 2001;72:1950-6

12. Tyagi SC, Lewis K, Pikes D, Marcello A, Mujumdar VS, Smiley LM, et al. Stretch-induced membrane type matrix metalloproteinase and tissue plasminogen activator in cardiac fibroblast cells. J Cell Physiol. 1998; 176:374-82.

13. Streeter DD Jr, Spotnitz HM, Patel DP, Ross J Jr, Sonnenblick EH. Fiber orientation in the canine left ventricle during diastole and systole. Circ Res. 1969;24:339-47.

14. LeGrice IJ, Smaill BH, Chai LZ, Edgar SG, Gavin JB, Hunter PJ. Laminar structure of the heart: ventricular myocyte arrangement and connective tissue architecture in the dog. Am J Physiol Heart Circ Physiol. 1995;269(suppl):H571-82.

15. Sonnenblick EH, Ross J Jr, Covell JW, Spotnitz HM, Spiro D. The ultrastructure of the heart in systole and diastole. Circ Res. 1967;21: 423-31.

16. Costa KD, Takayama Y, McCulloch AD, Covell JW. Laminar fiber architecture and three-dimensional systolic mechanics in canine ventricular myocardium. Am J Physiol Heart Circ Physiol. 1999; 276(suppl):H595-607.

17. Villarreal FJ, Lew WY, Waldman LK, Covell JW. Transmural myocardial deformation in the ischemic canine left ventricle. Circ Res. 1991;68:368-81.

18. Van Leuven SL, Waldman LK, McCulloch AD, Covell JW. Gradients of epicardial strain across the perfusion boundary during acute myocardial ischemia. Am J Physiol Heart Circ Physiol. 1994;267(suppl): H2348-62.

19. Waldman LK, Fung YC, Covell JW. Transmural myocardial deformation in the canine left ventricle. Normal in vivo three-dimensional finite strains. Circ Res. 1985;57:152-63.

20. Ashikaga H, Criscione JC, Omens JH, Covell JW, Ingels NB Jr. Transmural left ventricular mechanics underlying torsional recoil during relaxation. Am J Physiol Heart Circ Physiol. 2004;286:H640-7.

21. Niczyporuk MA, Miller DC. Automatic tracking and digitization of multiple radiopaque myocardial markers. Comput Biomed Res. 1991; 24:129-42.

22. Daughters GT, Sanders WJ, Miller DC, Schwartzkopf A, Mead CW, Ingels NB Jr. A comparison of two analytical systems for 3-D reconstruction from biplane videoradiograms. Computers in Cardiology (IEEE). Proceedings. 1988;Sep:79-82.

23. DeAnda A Jr, Moon MR, Nikolic SD, Castro LJ, Fann JI, Daughters GT. A method to assess endocardial regional longitudinal curvature of the left ventricle. Am J Physiol Heart Circ Physiol. 1995;268(suppl): H2553-60. 
24. Moon MR, Castro LJ, DeAnda A, Daughters GT, Ingels NB Jr, Miller DC. Effects of left ventricular support on right ventricular mechanics during experimental right ventricular ischemia. Circulation. 1994; 90(suppl II):II92-101.

25. Rodriguez F, Langer F, Harrington KB, Tibayan FA, Zasio MK, Cheng A, et al. Importance of mitral valve second-order chordae for left ventricular geometry, wall thickening mechanics, and global systolic function. Circulation. 2004;110(11 Suppl 1) II115-22.

26. McCulloch AD, Omens JH. Non-homogeneous analysis of threedimensional transmural finite deformation in canine ventricular myocardium. J Biomech. 1991;24:539-48.

27. Dou J, Tseng WY, Reese TG, Wedeen VJ. Combined diffusion and strain MRI reveals structure and function of human myocardial laminar sheets in vivo. Magn Reson Med. 2003;50:107-13.

28. Athanasuleas CL, Stanley AW Jr, Buckberg GD, Dor V, DiDonato M, Blackstone EH. Surgical anterior ventricular endocardial restoration (SAVER) in the dilated remodeled ventricle after anterior myocardial infarction. RESTORE group. Reconstructive Endoventricular Surgery, returning Torsion Original Radius Elliptical Shape to the LV. J Am Coll Cardiol. 2001;37:1199-209.

29. Kelley ST, Malekan R, Gorman JH III, Jackson BM, Gorman RC, Suzuki Y, et al. Restraining infarct expansion preserves left ventricular geometry and function after acute anteroapical infarction. Circulation. 1999;99:135-42.

\section{Discussion}

Dr Mark Ratcliffe (San Francisco, Calif). I have a simple technical question. How did you define the border zone? It is a very interesting study, a very nice study.

Dr Rodriguez. Thank you very much. We defined a functional border zone by using our global LV marker array to calculate regional systolic FAS, which allowed us to precisely determine which ventricular regions experienced the functional ischemic insult.

Dr Ratcliffe. But you must have put a set of beads right into the area that you thought was going to be the border zone.

Dr Rodriguez. We did, and to be honest, that was fortuitous. When we placed the beads, we were consistent with their placement in the midlateral wall, straddling the line created between our equatorial and apical lateral wall markers. When we performed the FAS analysis, we found that our beads were located right in the area between the ischemic posterolateral and nonischemic anterolateral regions, which enabled us to analyze the strain alterations in this functional border zone.

Dr Ratcliffe. One of the studies that we have been interested in was a study that was done at Washington University by Mike Pasque's group in which they actually showed that there was some extension during isovolumic systole. Did you break down systole into separate parts, and if so, what did you find?

Dr Rodriguez. Yes. In fact, I actually used some of the findings from that report to guide my discussion. For clarity, we chose to report end-systolic strains only, although we were able to analyze transmural strains throughout systole. In studying the subendocardial fiber strain patterns, remembering that we care about what strains the fibers are seeing rather than simply cardiac coordinate strains, we did in fact observe that the subendocardial fibers were stretched during isovolumic contraction. From this stretched configuration in early systole, the end-systolic strain analysis revealed that the fibers had returned to their initial enddiastolic length (ie, zero strain from end-diastole). This is why I was able to say in the presentation that the fibers had stretched during systole. These findings are similar to the midwall fiber stretch that was reported in the Washington University study to which you are referring. Because the fibers in the midwall are oriented circumferentially, these investigators were able to appreciate midwall fiber stretch when they observed circumferential lengthening in the midwall during isovolumic contraction with their magnetic resonance imaging study.

Dr Robert C. Robbins (Stanford, Calif). What about longerterm ischemia? Seventy seconds, is that how long you occluded the circumflex? And did you acquire data during that 70-second time period or after reperfusion? Can you clarify for us what you did?

Dr Rodriguez. Absolutely. We occluded the midcircumflex artery for 70 seconds. After this initial period of 70 seconds, we kept the midcircumflex occluded while we acquired our data. Because the data are from 3 beats, they were acquired very quickly. We believed that this initial acute study was important because any measured strain alterations would occur before any molecular processes would be initiated because it was only after 70 seconds of ischemia.

And now, fortunately, in our laboratory Dr Frank Langer has just recently completed an analysis of chronic infarct data in animals that sustained posterolateral infarctions and were then followed out for 8 weeks. Data from these infarcted animals were compared with data from a sham set of experiments that had beads implanted in the same midlateral region and then followed for 8 weeks with nothing else done. This analysis shows that the same increased circumferential-radial shear, which we observed during acute ischemia, is in fact preserved and somewhat magnified after 8 weeks.

Dr Robbins. What were the technical issues? You might tell us more than we want to know, but what were the technical issues that prevented you from getting strain data in 4 of the animals?

Dr Rodriguez. Thank you for that question. Before we can make our quantitative microstructural measurements, it is very important that we rapidly fix the LV in situ by using glutaraldehyde, with the ventricular pressure matched to the in vivo enddiastolic pressure. This is necessary so that we can use linear algebra to mathematically transform our calculated cardiac strains into fiber-sheet strains by using the transmural fiber angle and sheet angle measurements that were made from this end-diastolic configuration. During our initial learning period for this experiment, we were unable to obtain adequate fixation in 4 of the animals. Consequently, the ventricles in these 4 animals were soft. Although these 4 animals provided cardiac strain data, they were excluded from the fiber-strain analysis because too many assumptions would have been made with their microstructure to reliably determine fiber-sheet strains.

Dr Ross M. Ungerleider (Portland, Ore). I had the same question about the location of the beads because it seems to me that your conclusions are really dependent on being in the border zone, and I am just curious whether you could describe for us what the differences might be like if the beads were in the infarct zone versus far away from the border zone.

Dr Rodriguez. Actually, Dr Covell in San Diego, from whom we learned and acquired much of this transmural bead strain technology, performed a similar study in which he actually studied transmural bead deformations in the ischemic region, and when we compared the alterations in our border zone strains with what they observed in the ischemic myocardium, there were marked differ- 
ences. In their study systolic circumferential and longitudinal stretching and transmural radial wall thinning were observed, with reversal of transmural circumferential-longitudinal, circumferential-radial, and longitudinal-radial shears in the ischemic myocardium. In contrast, longitudinal shortening was reduced throughout the wall but not stretched, and circumferential-radial shear increased in the border zone. No changes in circumferential strain were observed. These marked differences led us to be confident. In addition, when we were doing the operation, every animal had the global epicardial markers placed in the same locations by the same surgeon. Then after the epicardial markers were placed, we used echocardiography to identify a place between the papillary muscles that the transmural beads could be inserted. It was always the same place, directly below the lateral equatorial marker in the LV free wall. Therefore when I showed the figure illustrating the marker grid pattern with the beads immediately below the lateral equatorial marker, that is exactly where the beads were located. 